\title{
ЦИФРОВИЗАЦИЯ СТРОИТЕЛЬНОЙ ОТРАСЛИ В РФ
}

\author{
Москвичев Максим Андреевич \\ аспирант \\ Научный руководитель: Морозова Ирина Анатольевна \\ д.э.н., профессор \\ ФГБОУ ВО «Волгоградский государственный \\ технический университет»
}

Аннотация: Цифровизация строительной отрасли будет развиваться по многим направлениям обеспечивающим переход к системе управления жизненным циклом объектов капитального строительства.

Ключевые слова: Экономика, цифровизация строительной отрасли.

\section{DIGITALIZATION OF THE CONSTRUCTION INDUSTRY IN THE RUSSIAN FEDERATION}

\section{Moskvichev Maxim Andreevich Morozova Irina Anatolyevna}

\begin{abstract}
The digitalization of the construction industry will develop in many directions, ensuring the transition to a life cycle management system for capital construction objects.
\end{abstract}

Key words: Economics, digitalization of the construction industry.

Строительная отрасль, как и российская экономика в целом, находятся перед долговременными системными вызовами, отражающими как мировые тенденции, так и внутренние барьеры развития. Строительство в экономике страны представляет собой межотраслевой комплекс, который предназначен для ввода в действие новых, а также для ремонта, реконструкции и технического перевооружения действующих объектов непроизводственного и производственного назначения. Анализ развития этой стратегически значимой отрасли за последние 10 лет свидетельствует об устойчивом развитии стагнационных процессов, обусловленных, во многом, ограниченностью бюджетных ресурсов, снижением инвестиционной активности, невысокими 


\section{СОВРЕМЕННЫЕ ИССЛЕДОВАНИЯ КАК ДРАЙВЕР РОСТА ЭКОНОМИКИ И СОЦИАЛЬНОЙ СФЕРЫ}

инновационными характеристиками, что повлияло на снижение конкурентоспособности как отрасли в целом, так и отдельных субъектов строительного рынка. Объем работ по виду деятельности «Строительство» за 2018 год составил 8,4 трлн. руб., из них за счет госкапвложений - 1,5 трлн. руб. или 18\%. Приведение этого показателя к ценам 2005 года показало, что прирост объемов работ по виду деятельности «Строительство» в 2016-2018 годах был невысоким и не обеспечил достижения уровня 2012-2013 годов. Сегодня совокупный валовый продукт строительной отрасли составляет 8,4 трлн. руб., или около 8\% ВВП. А вместе с промышленностью строительных материалов (1,5 трлн. руб.) и ЖКХ (5 трлн. руб.) достигает 15 трлн. руб., что составляет около 15\% ВВП. Доля государственных инвестиций в основные фонды в 2018 году составила 16\%, негосударственных - 84\%. Распределение инвестиций в жилищное строительство: частные - 94,4\%, государственные 2,6\%, прочие 3\% (годовой объем около 4 трлн. руб.). Такое распределение инвестиций на фоне продолжающего с 2014 года ежегодного снижения реальных доходов населения привело к сокращению объемов ввода жилья с 85,4 млн. кв. м в 2015 году до 75,7 млн. кв. м в 2018 году. Прослеживается прямая зависимость между объемом работ по виду деятельности «Строительство» и такими показателями как: - рост валового внутреннего продукта Российской Федерации; - уровень инвестиций в основной капитал; реальные доходы населения. Эта зависимость отражается не только на общем объеме строительных работ, но и на динамике ввода жилья. Частичная компенсация этой зависимости возможна за счет развития ипотечного жилищного кредитования, которое, в свою очередь, зависит от средней ставки по ипотечному кредиту и уровня реальных доходов населения. Повышение уровня реальных доходов населения в сочетании с развитием ипотечного жилищного кредитования может привести к существенному мультипликативному эффекту не только по отношению к объемам строительных работ, но и к ВВП[4, с. 4].

Обеспечение эффективности функционирования и устойчивого положения строительных организаций на рынке затруднительно без применения научно обоснованного подхода к повышению конкурентоспособности. Все это подтверждает актуальность исследования в области повышения конкурентоспособности строительных организаций в условиях цифровой экономики. Цифровизация строительной отрасли будет 


\section{СОВРЕМЕННЫЕ ИССЛЕДОВАНИЯ КАК ДРАЙВЕР РОСТА ЭКОНОМИКИ И СОЦИАЛЬНОЙ СФЕРЫ}

развиваться по многим направлениям, обеспечивающим переход к системе управления жизненным циклом объектов капитального строительства.

Строительная отрасль формирует заказ на поиск оптимальных технологических, технических и организационных решений, обладающих мультипликативным эффектом для всей экономики, этим самым решая масштабные экономические задачи. Более эффективному решению задач в строительной отрасли требуются наращивания объемов строительства жилья, реализации масштабных инфраструктурных проектов, открывающие возможности для развития промышленно-экономического потенциала Российской Федерации в целом.

Цифровизация строительной отрасли будет развиваться по многим направлениям, обеспечивающим переход к системе управления жизненным циклом объектов капитального строительства.
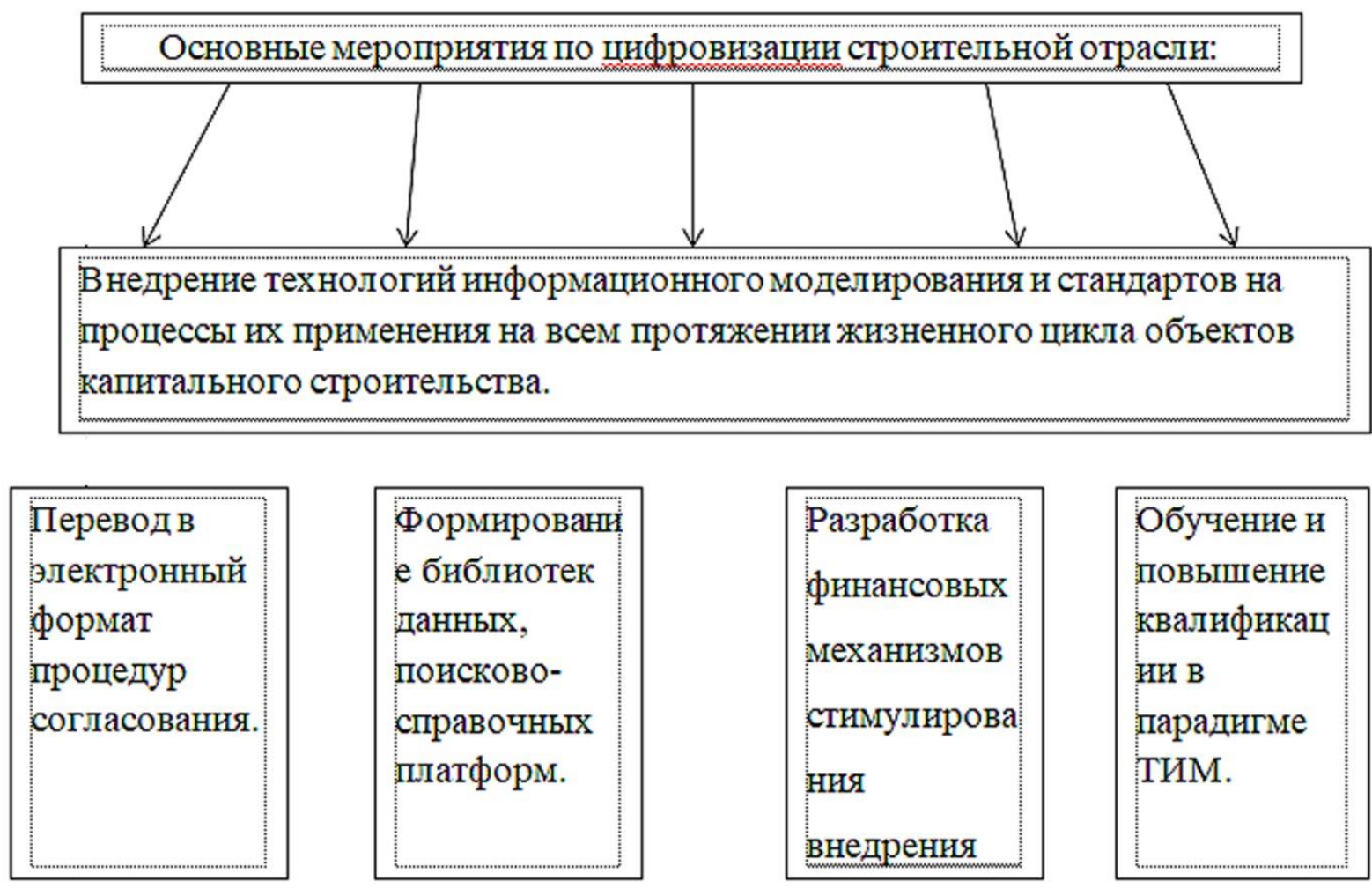

Обучение и
повышение
квалификац
ин в
парадигме
ГИМ.

Согласно стратегии развития строительной отрасли Российской Федерации целевые показатели к 2030 году: 


\section{СОВРЕМЕННЫЕ ИССЛЕДОВАНИЯ КАК ДРАЙВЕР РОСТА ЭКОНОМИКИ И СОЦИАЛЬНОЙ СФЕРЫ}

- ввод жилья до 120 млн. кв. м общей площади жилья в год к 2024 году; 86 - ввод индивидуальных жилых домов, возводимых с использованием индустриальных технологий, на уровне не менее 60 млн. кв. м общей площади жилья в год - объем жилищного фонда - 4,7-5,0 млрд. кв. м общей площади жилья; - уровень обеспеченности населения жильем, - 33 кв. м общей площади жилья на человека; - доля домохозяйств, удовлетворенных жилищными условиями - 75\%;

- использование технологий ТИМ, в процентах от числа проектов с государственными капвложениями - 50\%;

- доля объектов капитального строительства, возводимых с использованием бюджетных средств и имеющих информационную модель, - 85\%;

- наличие платформ, хранилищ информационных моделей, баз данных должно обеспечивать потребности не менее 50\% проектировщиков;

- доля специалистов проектных организаций, прошедших повышение квалификации для работы с информационными моделями $-80 \%$.

В качестве одного из примеров уже начавшейся цифровизации строительной отрасли можно рассматривать проект «Умный город», реализуемый Минстроем России в рамках национальной программы «Цифровая экономика» и национального проекта «Жилье и городская среда». Этот проект направлен на формирование эффективной системы управления городским хозяйством, повышение конкурентоспособности российских городов, создание комфортных и безопасных условий для жизни горожан и базируется на 5 ключевых принципах:

- ориентация на человека;

- технологичность городской инфраструктуры;

- безопасная и комфортная среда;

- повышение качества управления городскими ресурсами;

- акцент на экономической эффективности, сервисной составляющей городской среды.

Широкое внедрение передовых цифровых и инженерных решений в городской и коммунальной инфраструктуре это основной инструмент реализации этих принципов[4, с. 115]. 
Требования проекта «Умный город» необходимо учитывать при разработке градостроительной документации, в том числе по следующим направлениям:

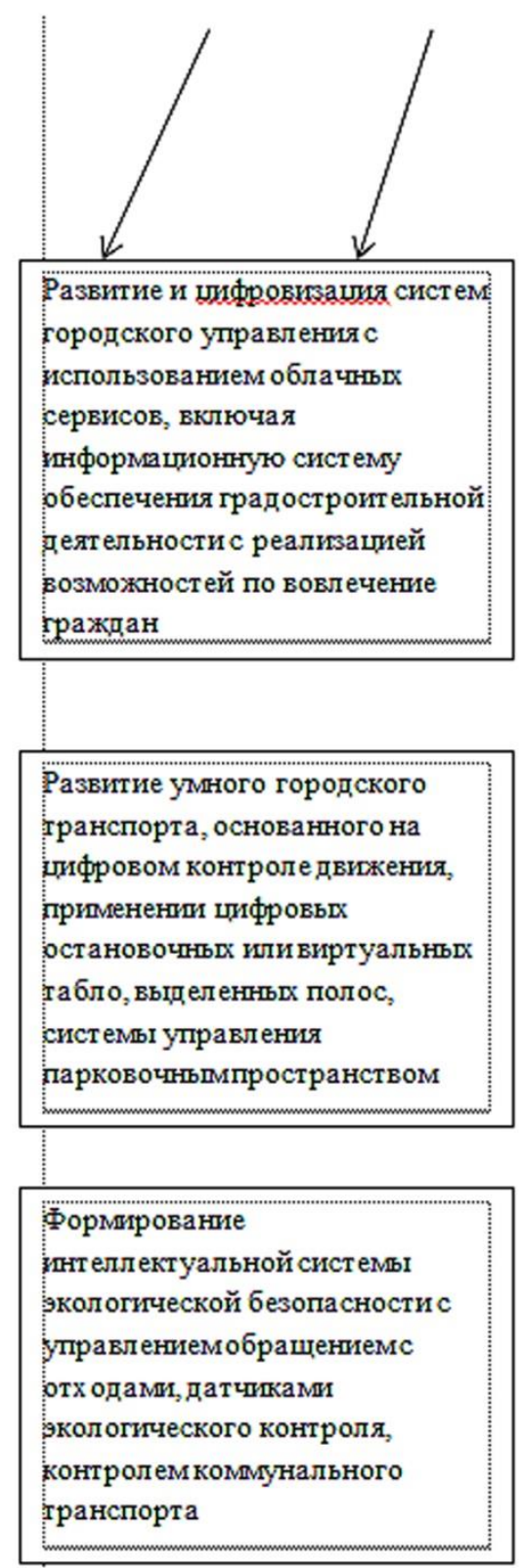

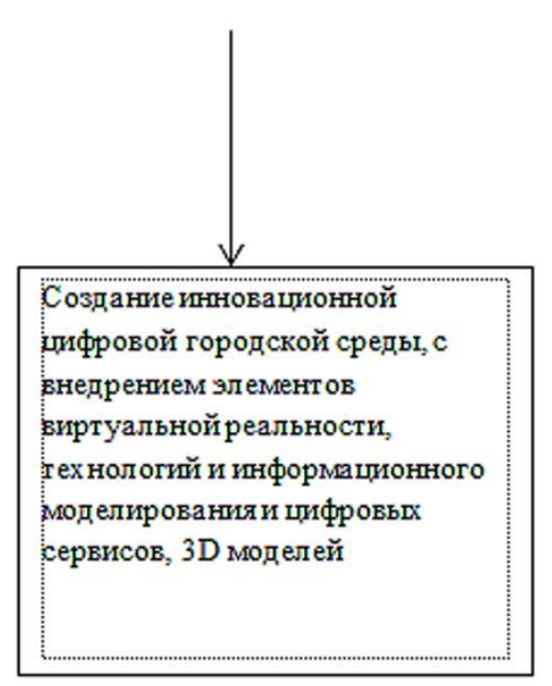

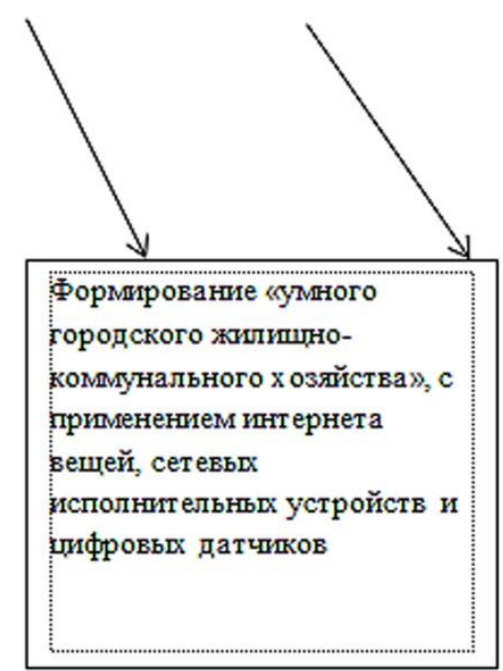

Совершенствование

интеллектуальньх систем безопасностина основе ведения и х ранения видеозаписей, автоматического увед омления службы спасения, систем ир ентификации

Обеспечение развитие туризма и сервиса с внедрением облачньг сервисов, электронньг карт, QRкодов на

дост опримечат ельност жx, использованием RFID-мет ок

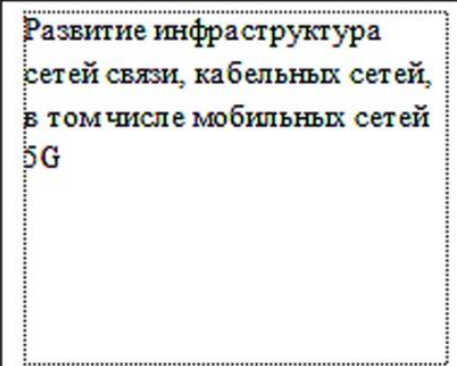




\section{СОВРЕМЕННЫЕ ИССЛЕДОВАНИЯ КАК ДРАЙВЕР РОСТА ЭКОНОМИКИ И СОЦИАЛЬНОЙ СФЕРЫ}

\section{Основными результатами реализации мероприятий, являются:}

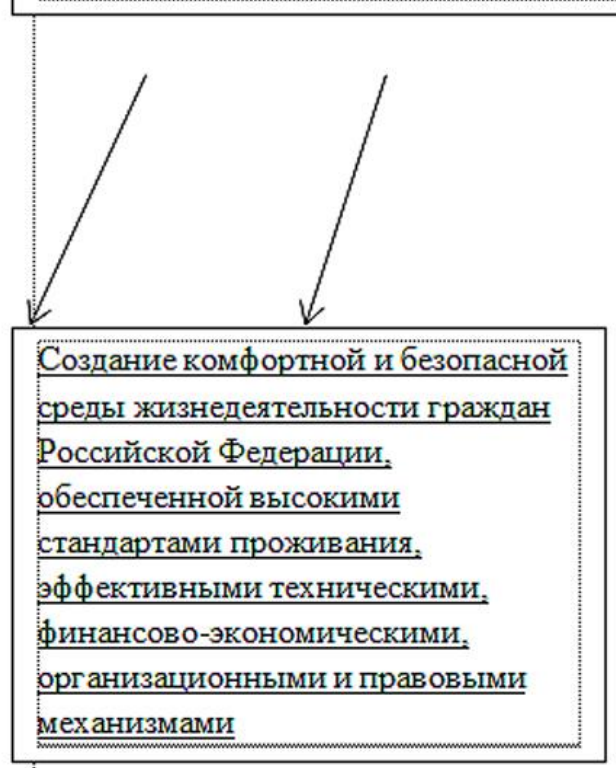

Ежегодный ввод за счет всех источников финансирования в действие жилых домов - не менее 120 млн. Кв. м общей площ ади жилья
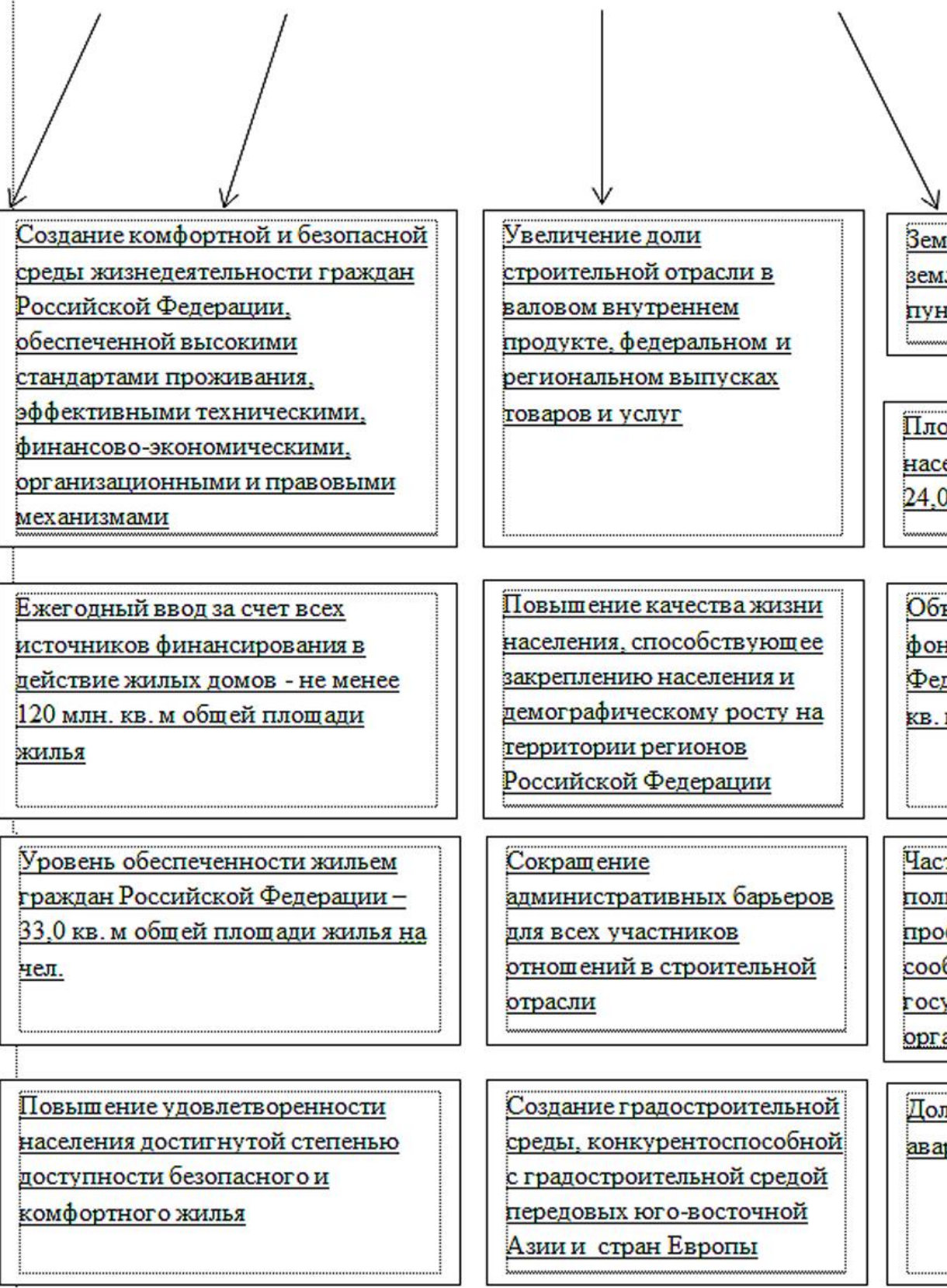

Земли застройки В землях населенных пунктов $-6,0$ млн. га продукте, федеральном и региональном выпусках товаров и услуг
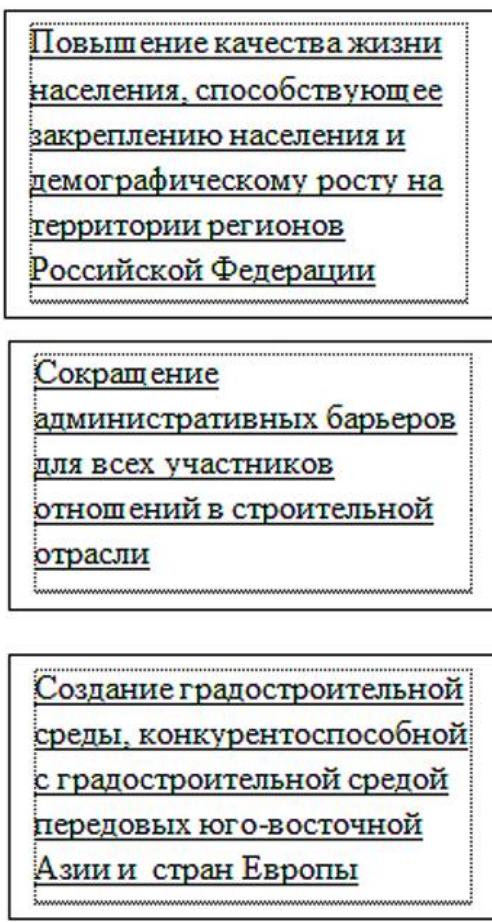
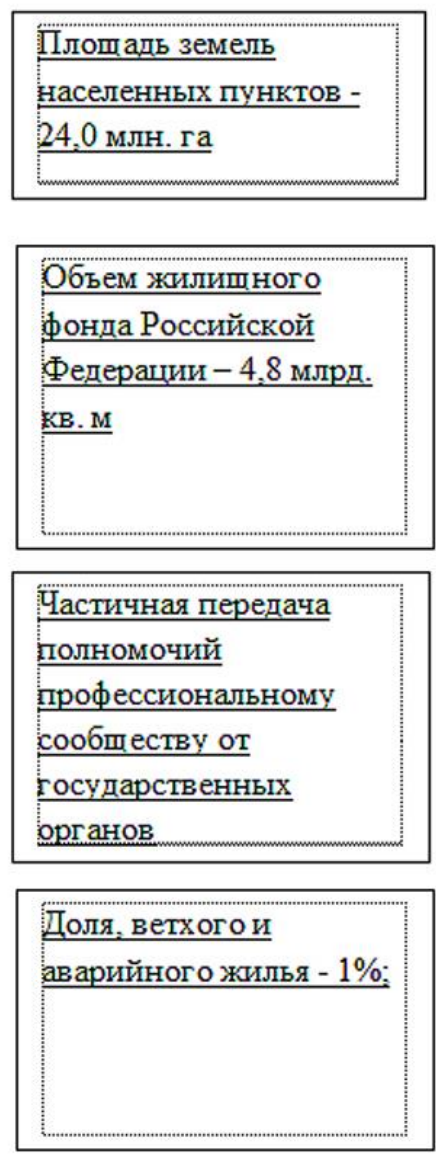

Завершение разработки законодательных требований (в том числе по госзакупкам), механизмов финансирования, а также формирования запасов домокомплектов быстровозводимых малоэтажных жильг домов в каждом федеральном округе для обеспечения возможности быстрого расселения жителей малых поселений в случаях возникновения чрезвычайных ситуаций

Повыпение качества системы
архитектурно-строительного образования
и успешное формирование кадрового
потенциалав сфере градостроительства.
инженерных изысканий, проектирования
и строительства, архитектуры, развитие
отраслевой науки




\section{СОВРЕМЕННЫЕ ИССЛЕДОВАНИЯ КАК ДРАЙВЕР РОСТА ЭКОНОМИКИ И СОЦИАЛЬНОЙ СФЕРЫ}

Таким образом, резюмируя, хочется сказать, что строительная отрасль в России имеет хороший потенциал к цифровизации. Значительное число наиболее прогрессивных строительных организаций внедряет в свою работу новые технологии, видя их высокий потенциал и эффективность. Поэтому начавшаяся сейчас на государственном уровне работа по «легализации» технологий информационного моделирования имеет большие шансы на успех.

\section{Список литературы}

1. Кощеев В.А., Цветков Ю.А., Вишнивецкая А.И. Элементы цифровой экономики в жилищно-коммунальном хозяйстве // Вестник гражданских инженеров. - 2019. -№ 2. - с. 173-179. - doi: 10.23968/1999-5571-2019-16-2173-179 .

2. Гридчина А.В. Методология разработки стратегий конкурентоспособности организации // Вестник Белгородского университета потребительской кооперации. -2006. - № 2. - с. 57-68.

3. Метелев И.С. Конкурентоспособность субъекта предпринимательской деятельности: сущность, методы, факторы и критерии оценки // Региональные проблемы преобразования экономики. - 2011. - № 1. с. 111-122.

4. Проект «Стратегия развития строительной отрасли Российской Федерации до 2030 года» 